\title{
Slow-moving journals hinder conservation efforts
}

\author{
Critical policy decisions miss out on research stuck in an 18-month publishing queue.
}

Sir - Conservation biology is a crisis discipline, burdened with the responsibility of providing rapid scientific answers that can help us protect our world's threatened biodiversity ${ }^{1}$. Because we lack basic natural-history information regarding thousands of species on the precipice of extinction, there is a clear opportunity for biological research to make valuable 'real world' contributions. Indeed, conservation science can play a timely and pivotal role in judicial and legal decisions about resource policy ${ }^{2}$.

However, to make a meaningful contribution to conservation decisions, scientific input is often needed on the timescale of months, rather than the years typical of many major scientific journals. Because of the urgency surrounding conservation, we investigated the speed with which the major conservation-biology journals publish research relative to comparable journals in organismal biology. Our results are disquieting. Rather than being faster, in response to the biodiversity crisis, leading journals in conservation biology are the slowest to publish primary research.

To discover how long it takes an original scientific finding to find its way into the peer-reviewed literature, we examined a wide array of biological journals and recorded the time in days from submission to publication for every research paper appearing in 2000. We excluded journals that appear more often than bi-weekly or less often than quarterly, or that fail to list the dates on which manuscripts were both received and accepted, and we focused on research articles (excluding special features, commentaries and essays). We selected journals to represent four categories: conservation and applied ecology; taxonomically oriented research; behaviour; and evolution and genetics. Within each category, we selected journals that have the highest science-impact scores ${ }^{3}$ or that represent the largest professional scientific societies. Journals satisfying both criteria were chosen first.

Among the examined journals, the three conservation and applied-ecology journals stand out as having the slowest publication processes (Fig. 1), with an average median lag time of 572.2 days from submission to publication. In contrast, the four genetics and evolution journals had an average median lag time of only 249.1 days. It is noteworthy that three of the four journals in this 'fastest class' encourage or require online submission, whereas none of the conservation journals allows online submission.

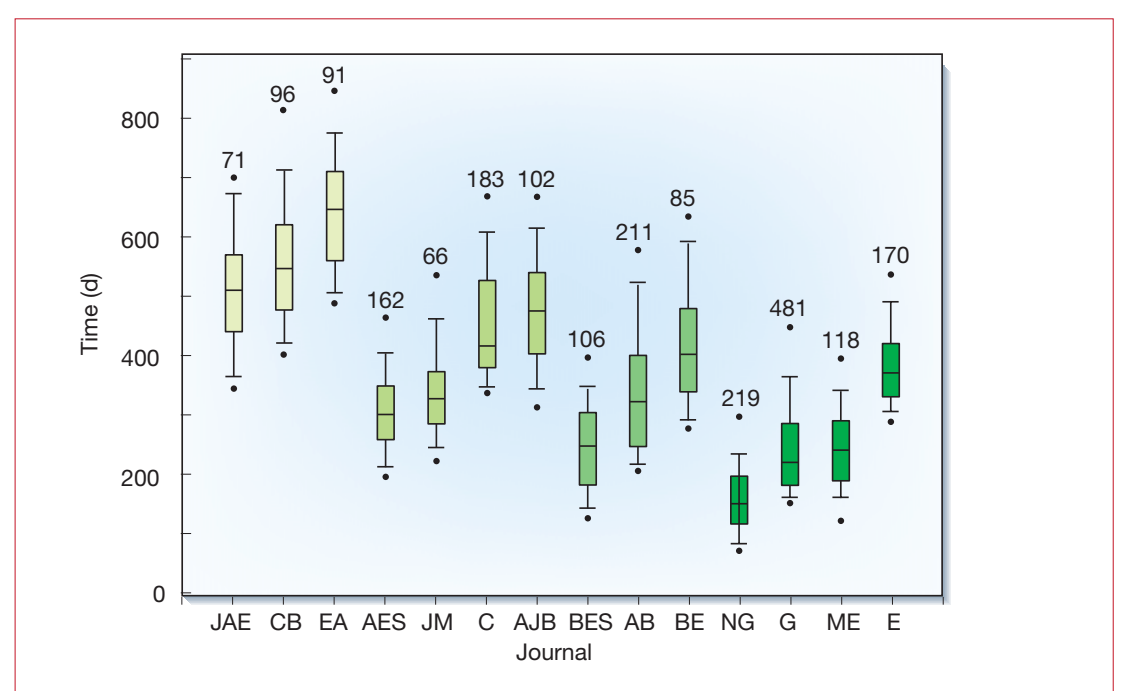

Figure 1 Median time, in days, from submission to publication for journals representing four disciplines within organismal biology. Conservation and applied ecology (yellow columns): JAE, Journal of Applied Ecology; CB, Conservation Biology; EA, Ecological Applications. Taxonomic (light green): AES, Annals of the Entomological Society of America; JM, Journal of Mammalogy; C, Condor; AJB, American Journal of Botany. Behaviour (medium green): BES, Behavioral Ecology and Sociobiology; AB, Animal Behaviour; BE, Behavioral Ecology. Evolution and genetics (dark green): NG, Nature Genetics; G, Genetics; ME, Molecular Evolution; E, Evolution. Extent of the boxes indicates 25 th and 75 th percentiles, lines within boxes represent medians, capped bars represent 10th and 90th percentiles, and circles represent 5 th and 95 th percentiles. Numerical labels are sample sizes.

We believe that the leading journals in the area of conservation biology have a heightened responsibility for rapid dissemination of research results. Our survey indicates that these scientific outlets are not measuring up to this responsibility. If conservation biology truly is a crisis discipline, then the discipline's journals must make rapid handling of submitted research articles a high priority. Otherwise, if we cannot rapidly publish science concerning threats to biodiversity, opportunities for conservation action could be missed and species may pay the price for our procrastination.

Peter Kareiva $^{\star} \dagger$, Michelle Marvier $\dagger$, Sabrina West $\dagger$, Joy Hornisher $\dagger$

${ }^{*}$ The Nature Conservancy, 217 Pine Street, Suite 1100, Seattle, Washington 98101, USA

$\dagger$ Environmental Studies Institute, Santa Clara University, Santa Clara, California 95053, USA

1. Wilson, E. O. Conserv. Biol. 14, 1 (2000).

2. Harrison, S., Stahl, A. \& Doak, D. Conserv. Biol. 7, 950 (1993).

3. ISI Journal Citation Reports (Institute for Scientific Information, Philadelphia, 2000).

\section{Sharp eyes saw through early effort to fake prints}

Sir - While surveying the history of fingerprinting at the National Archives of India in New Delhi, we came across an early reference to forged fingerprints, similar to that described in your fascinating News item "Detectors licked by gummy fingers" (Nature 417, 676; 2002, and see D. Ehrenfeld, Nature 418, $583 ; 2002$ ).

In 1917, when the science of fingerprinting was in its infancy, news of a demonstration by a lawyer in a court in Howrah (Bengal, India) threatened to undermine the value of this discipline
(Home Department Proceedings 202-206 (A), Police Branch, Government of India, August 1919).

The lawyer, Babu Panchkowry Chatterji, was then invited to Bengal Fingerprint Bureau and asked to redemonstrate his experiment. He took a thin piece of paper and smeared it lightly with gum arabic. He then placed it over a fingermark and pressed it for one to two minutes. Next, he slightly wetted the paper and separated it from the original impression so that it now carried the negative of the imprint. He applied the negative to a fresh sample of paper, wetted and pressed it again, and removed it, thus producing a clear replica of the original 
impression. The original fingermark was not damaged by this process.

These findings made sensational news. It was feared that astute money lenders would implant borrowers' thumbprints on fresh proforma and fill in larger amounts and/or higher rates of interest. When the case was referred to F. Brewester, the then Government Examiner of Questioned Documents, he submitted himself to a test prepared by Howrah Bar. The test consisted of 12 fingerprints - a random mix of genuine and transferred ones - on a single sheet of paper. He was asked to segregate them. In one attempt, Brewester identified the forged fingerprints. He noticed three differences: the transferred prints had diffuse lines while the originals had sharp patterns; the transferred prints were impregnated with gum; and the fibres on the part of the paper with transferred prints were disoriented.

Brewester therefore concluded that an observant fingerprint expert can easily differentiate an original mark from a transplanted one.

G. S. Sodhi* ${ }^{\star}$ Jasjeet Kaur $\dagger$

${ }^{*}$ S. G. T. B. Khalsa College, University of Delhi, Delhi-110007, India

$\dagger$ Rajguru College of Applied Sciences for Women, University of Delhi, Delhi-110095, India

\section{Science and government share anti-terrorist goals}

Sir-Your news article headlined "National academies slam Bush proposal for data security" (Nature 419, 769; 2002) mischaracterizes the debate here in Washington by its very title. It also leads readers to believe, erroneously, that I said that "without written guidelines, scientists can't accept [President Bush's science adviser, John] Marburger's assurances".

The statement "Science and Security in an Age of Terrorism", published on 18 October by the presidents of the National Academy of Sciences, the National Academy of Engineering and the Institute of Medicine, recognizes the need "to achieve an appropriate balance between scientific openness and restrictions on public information" when strategic secrets are at stake. But it also asks our government to maintain the current clear distinctions between classified and unclassified research, and recommends against poorly defined categories of "sensitive but unclassified" information that do not provide "precise guidance on what information should be restricted from public access".

The statement also asks the Bush administration to reaffirm a national security directive signed by President
Ronald Reagan in 1985 which held that "no restrictions may be placed upon the conduct or reporting of federally funded fundamental research that has not received national security classification".

In the wake of 11 September 2001, all of us in science and government have been forced to soberly reassess our roles concerning research touching on possible terrorist threats. No US scientist wants to publish research in a form that could be helpful to terrorists. Similarly, no US government official should want to hinder (or worse, stop) scientific research that might lead to effective tools against terrorism.

Scientists and government are listening to each others' legitimate concerns, and the government wants to enlist scientists in its anti-terrorism policies. In January, the National Academies plan to host a town meeting in which scientists, scientific publishers, national-security experts and government officials can talk face to face.

Marburger, director of the White House Office of Science and Technology Policy, is a key partner in these discussions. He informs us of the administration's concerns as well as communicating scientists' and scientific organizations' concerns to the White House. This is why I was disturbed at your implication that I said scientists couldn't rely on Marburger's assurances. That is simply wrong. The Bush administration has not yet even formulated its ultimate policy on this issue.

At the National Academies, we have never doubted Marburger's intentions or his goodwill. We share the same goal: to harness and focus the considerable energies of the science, engineering and health communities in the complex, rapidly changing challenge of counter-terrorism.

\section{E. William Colglazier}

National Academy of Sciences and National Research Council, 2101 Constitution Avenue Northwest, Washington DC 20418, USA

\section{Peer review to select academic job applicants}

Sir - Assessing the quality of candidates for academic positions has been the subject of controversy. Problems include nepotism and inbreeding, lack of impartiality among committee members - as M. Soler noted in Correspondence (Nature 411, 132; 2001) - and the increasing use of impact factors as indicators of research performance (see, as one of many examples, Nature 415, 726-729; 2002).

We suggest, as an alternative, that peer review could be a fairer method of research evaluation when scientists are being assessed for new jobs. To ensure the expertise and impartiality of peers, appointment committees should include internationally recognized scientists who are not affiliated with the institution where the position is offered.

Operational costs could be kept low by use of e-mail, the Internet, videoconferencing and so on. Such cost-effective implementation would be of particular benefit to academic institutions in developing countries, which could call on a broader choice of specialists to comprise virtual appointment committees.

Rigorous criteria, relevant to the position, could be laid down before the job is advertised. These criteria might include originality of ideas, diversity of approaches, appropriateness of methods, statistical design and analyses, and so on. Candidates could then be assessed on the kind of quantitative scale that many journals use.

To that end, a comprehensive account of the candidate's research contributions, together with relevant published papers, can be presented without the journals' or the candidate's identities being revealed, so research committees can focus on scientific quality irrespective of journals' impact factors and potential personal biases. Moreover, the identity of the committee should be made public, to safeguard the impartiality of the selection process and the confidence of candidates.

Peer review has undeniably contributed to the advancement of science by providing a reliable system of quality control validated by experts. Some of the criticisms of its use (such as plagiarism and competition) are unlikely to apply to the selection of new academic staff, as it is usually a candidate's past achievements rather than ideas, methods or data - that are under assessment.

No system is foolproof, and other criticisms of peer-review may apply to individual assessment — for example, sexism, opposing interests and lack of support for controversial ideas. However, these can be minimized by a policy of blind review, by having candidates specify potential conflicts of interest beforehand, and by including referees with different perspectives.

In summary, we believe that electronic information technologies can enhance the quality of recruitment systems in academic institutions by enabling the widespread use of peer review. This would be an improvement on current methods such as the impact factor, which is not a reliable measure of scientific excellence.

Esteban Fernández-Juricic, Wladimir J. Alonso, Cynthia Schuck-Paim

Department of Zoology, University of Oxford, Oxford OX1 3PS, UK 